\title{
Rapid (30-second), equipment-free purification of nucleic acids using easy-to-make dipsticks
}

\author{
Michael G. Mason $\circledast^{凶}$ and José R. Botella $\circledast^{凶}$
}

The complexity of current nucleic acid isolation methods limits their use outside of the modern laboratory environment. Here, we describe a fast and affordable method to purify nucleic acids from animal, plant, viral and microbial samples using a cellulose-based dipstick. Nucleic acids can be purified by dipping in-house-made dipsticks into just three solutions: the extract (to bind the nucleic acids), a wash buffer (to remove impurities) and the amplification reaction (to elute the nucleic acids). The speed and simplicity of this method make it ideally suited for molecular applications, both within and outside the laboratory, including limited-resource settings such as remote field sites and teaching institutions. Detailed instructions for how to easily manufacture large numbers of dipsticks in house are provided. Using the instructions, readers can create more than 200 dipsticks in $<30$ min and perform dipstick-based nucleic acid purifications in 30 s.

Development of the protocol

Worldwide, human, animal and plant diseases inflict a large toll on society in terms of human health, loss of food production and substantial financial costs $^{1-3}$. The current COVID-19 pandemic ${ }^{4}$ underscores how the high volume of international travel and trade in today's society can result in the rapid spread of diseases around the world. Accurate and sensitive diagnostics that help to identify the location of the disease and determine the effectiveness of the control measures are critical to disease management. Thus, the development of diagnostic tools and technologies that can make disease testing cheaper, easier and more accessible will help support disease management and reduce the toll of disease on society.

In 2017, we reported a new diagnostic tool that enables the purification of both DNA and RNA from humans, animals, plants, microbes or viruses within $30 \mathrm{~s}$ without any pipetting or electronic equipment ${ }^{5}$. We have taken advantage of the nucleic acid binding and release kinetics of cellulose matrices to create a dipstick that can rapidly bind nucleic acids from complex biological samples (e.g., crude extracts), retain them during a simple washing step and release them directly into the DNA amplification reaction. The dipsticks consist of a small $\left(8-16 \mathrm{~mm}^{2}\right)$ nucleic acid binding surface and a 40-50-mm long wax-impregnated water repellent handle to facilitate the procedure (Fig. 1). The dipstick format enables nucleic acid capture, purification and release to be performed in $<30 \mathrm{~s}$ by sequentially dipping the dipstick into the sample, wash and DNA amplification solutions. The method has worked for all sample types and organisms we have tried, and we have demonstrated that it works in conjunction with PCR, quantitative real time PCR (qPCR) and the isothermal DNA amplification methods loop-mediated DNA amplification (LAMP) and recombinase polymerase amplification (RPA) ${ }^{5}$. Nucleic acid elution from the dipsticks does not require a specific elution buffer and has been successfully achieved with water alone, although direct elution in DNA amplification mix provides greater nucleic acid recovery and thus improved diagnostic sensitivity.

A strength of the dipstick purification method is its adaptability to a wide variety of applications as demonstrated by its successful use with a large number of organisms and multiple buffer systems (Table 1). These data reveal that the dipstick purification method is a robust technology that is not dependent on a narrow set of conditions to function. The dipsticks require $<10 \mu \mathrm{l}$ of sample extract, which is a substantial advantage when the sample tissue is limited or when trace levels of target organisms need to be concentrated ${ }^{6}$. However, if larger sample extracts are prepared, the same extract can be used for multiple nucleic acid purifications. The risk of cross-contamination between samples

\footnotetext{
Plant Genetic Engineering Laboratory, School of Agriculture and Food Sciences, The University of Queensland, St Lucia, Queensland, Australia.

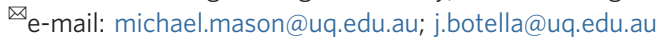




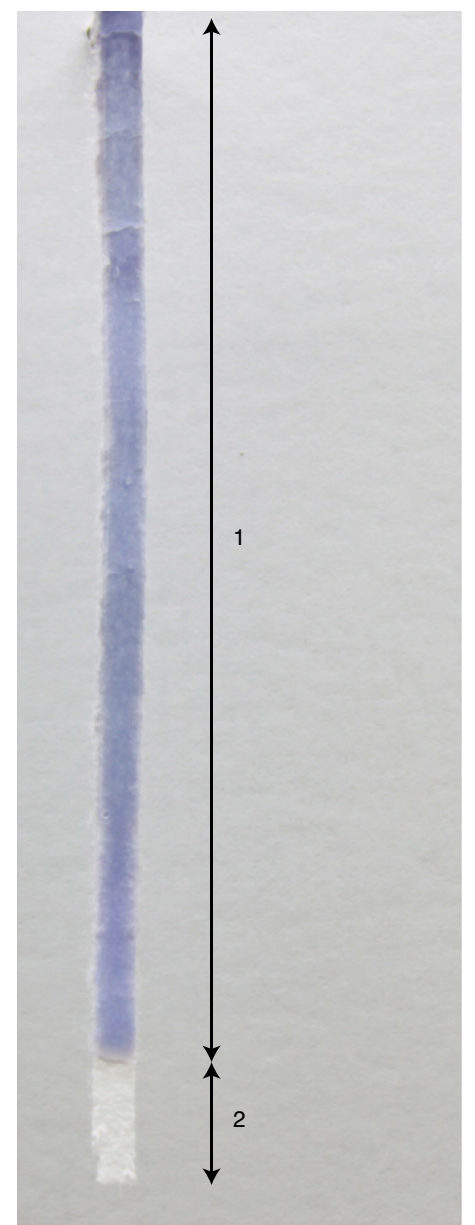

Fig. 1 | Nucleic acid-purifying dipstick. The dipstick is composed of two parts: (1) a 40- to 50-mm-long wax-impregnated handle, and (2) a $2 \times 6-\mathrm{mm}$ nucleic acid binding zone.

with the dipstick purification method is substantially reduced because each sample is processed sequentially, in contrast to traditional methods, in which samples are typically processed simultaneously. In addition, the speed of the purification process requires that aliquots of all reagents be prepared in advance and then immediately discarded after use, which further reduces the risk of cross-contamination.

Although a number of substrates can capture nucleic acids ${ }^{7-10}$, the novelty of our discovery is the transformation of a low-cost cellulose filter paper into a convenient dipstick that can rapidly purify nucleic acids from crude samples and elute them directly into the amplification mix without any pipetting. The dipstick method uses a mechanism of purification that is different from those of other systems; it is thought to take advantage of the differences between nucleic acids and other compounds in regard to their capture and retention kinetics by the cellulose matrix ${ }^{5}$. Large nucleic acid molecules are rapidly captured by the cellulose and retained during the wash step, whereas other, smaller compounds, including some DNA amplification inhibitors, either do not bind to the cellulose or are rapidly released into the wash solution. The combination of chemicals within the amplification reaction, as well as the liquid movement through the cellulose matrix (induced by the bending and compressing of the dipstick in the small reaction volume) result in nucleic acid release. The use of unmodified cellulose has substantial advantages over the use of other substrates because it enables nucleic acid binding and washing to be performed without denaturing chemicals, such as high salt concentrations, that may otherwise inhibit the DNA amplification reaction. The non-denaturing conditions also avoid the need for the traditional $70 \%$ ethanol wash and the additional time required to completely remove residual ethanol before elution, which would otherwise inhibit DNA amplification. 
Table 1 | Applications of the rapid nucleic acid purification technology

\section{Organism detected}

Human samples and pathogens

Human blood

Human cell line LM-MEL-70

Bacillus cereus in milk

\section{Campylobacter spp. on chicken meat}

\section{Animals and diseases}

Mouse (Mus musculus) ear clip and embryonic stem cells

Actinobacillus pleuropneumoniae from pig lung swab

Medaka (Oryzias latipes) and zebrafish (Danio rerio) embryos

Crayfish (Faxonella creaseri)

White spot syndrome virus in shrimp

\section{Insects}

Fruit fly (Drosophila melanogaster) and harlequin fly (Chironomus riparius)

\section{Crop diseases}

Rice blast (Magnaporthe oryzae) in leaves of rice cultivar Nipponbare

Cucumber mosaic virus in tomato leaves

Pseudomonas syringae pv. tomato strain DC3000 in Arabidopsis thaliana leaf tissue

Fusarium oxysporum f. sp. conglutinans in Arabidopsis thaliana leaf tissue

Phytophthora capsica in pepper leaves

\section{Crops}

Cassava (Manihot esculenta) leaves, cocoa (Theobroma cacao) leaves, coconut (Cocos nucifera) leaves and sawdust from stem drills Leaves of Arabidopsis thaliana, tobacco (Nicotiana benthamiana), tomato (Solanum lycopersicum), sugar cane (Saccharum officinarum), sorghum (Sorghum biocolor), soybean (Glycine max), rice (Oryza sativa), barley (Hordeum vulgare), wheat (Triticum aestivum), mandarin orange (Citrus reticulata), lime (Citrus aurantiifolia), lemon (Citrus limon), passion fruit (Passiflora edulis).

Lysis buffer

Wash buffer

Ref.

$800 \mathrm{mM}$ guanidine hydrochloride, $50 \mathrm{mM}$ Tris ( $\mathrm{pH} 8), 0.5 \%$ ( $\mathrm{vol} / \mathrm{vol})$ Triton $\mathrm{X}-100,1 \%$ ( $\mathrm{vol} / \mathrm{vol})$ Tween 20, $40 \mu \mathrm{g} / \mathrm{ml}$ Proteinase $\mathrm{K}$

$800 \mathrm{mM}$ guanidine hydrochloride, $50 \mathrm{mM}$ Tris ( $\mathrm{pH} 8$ ), 0.5\% (vol/vol) Triton X-100, 1\% (vol/vol) Tween 20

$50 \mathrm{mM}$ Tris ( $\mathrm{pH} 8.0$ ), $1.5 \mathrm{M}$ guanidine hydrochloride, $100 \mathrm{mM} \mathrm{NaCl}, 5 \mathrm{mM}$ EDTA, 1\% (vol/vol) Tween 20

$3 \mu \mathrm{g} / \mu \mathrm{l}$ proteinase $\mathrm{K}$ in TE buffer (10 $\mathrm{mM}$ Tris (pH 8), 1 mM EDTA)

$0.1 \mathrm{M}$ Tris- $\mathrm{HCl}(\mathrm{pH} 8.0), 5 \mathrm{mM}$ EDTA ( $\mathrm{pH}$ 8.0), $0.2 \mathrm{M} \mathrm{NaCl}, 1 \%$ (vol/vol) SDS

$1.5 \mathrm{M}$ guanidine hydrochloride, $50 \mathrm{mM}$ Tris ( $\mathrm{pH} 8)$, $100 \mathrm{mM} \mathrm{NaCl}, 5 \mathrm{mM}$ EDTA, 1\% (vol/vol) Tween 20

$0.4 \mathrm{M}$ Tris- $\mathrm{HCl}$ ( $\mathrm{pH} 8.0), 5 \mathrm{mM}$ EDTA ( $\mathrm{pH}$ 8.0), $0.15 \mathrm{M} \mathrm{NaCl}, 0.1 \%$ (vol/vol) SDS

$1 \% \mathrm{SDS}$ (vol/vol) and $0.5 \mathrm{M} \mathrm{NaCl}$

$20 \mathrm{mM}$ Tris ( $\mathrm{pH} 8.0$ ), $25 \mathrm{mM} \mathrm{NaCl}, 2.5 \mathrm{mM}$ EDTA and $0.05 \%$ (wt/vol) SDS

0.4 M Tris- $\mathrm{HCl}(\mathrm{pH} 8.0), 5$ mM EDTA ( $\mathrm{pH}$ 8.0), Water $0.15 \mathrm{M} \mathrm{NaCl}, 0.1 \%$ (vol/vol) SDS

$20 \mathrm{mM}$ Tris ( $\mathrm{pH}$ 8), $25 \mathrm{mM} \mathrm{NaCl}, 2.5 \mathrm{mM}$ EDTA, $0.05 \%$ (wt/vol) SDS

$800 \mathrm{mM}$ guanidine hydrochloride, $50 \mathrm{mM}$ Tris ( $\mathrm{pH} 8$ ), 0.5\% (vol/vol) Triton X-100, 1\% (vol/vol) Tween 20

$20 \mathrm{mM}$ Tris ( $\mathrm{pH} 8), 25 \mathrm{mM} \mathrm{NaCl}, 2.5 \mathrm{mM}$ EDTA, $0.05 \%$ (wt/vol) SDS

$50 \mathrm{mM}$ Tris (pH 8), $150 \mathrm{mM} \mathrm{NaCl}, 1 \%$ (wt/vol) Tween 20, 2\% (wt/vol) PVP-40

$20 \mathrm{mM}$ Tris ( $\mathrm{pH} 8$ ), $25 \mathrm{mM} \mathrm{NaCl}, 2.5 \mathrm{mM}$ EDTA, $0.05 \%$ (wt/vol) SDS

$50 \mathrm{mM}$ Tris ( $\mathrm{pH} 8$ ), $150 \mathrm{mM} \mathrm{NaCl}, 1 \%$ (wt/vol) Tween 20, 2\% (wt/vol) PVP-40

$50 \mathrm{mM}$ Tris ( $\mathrm{pH} 8$ ), $150 \mathrm{mM} \mathrm{NaCl}, 1 \%$ (wt/vol) Tween 20, 2\% (wt/vol) PVP-40

$20 \mathrm{mM}$ Tris ( $\mathrm{pH} 8), 25 \mathrm{mM} \mathrm{NaCl}, 2.5 \mathrm{mM}$ EDTA, $0.05 \%$ (wt/vol) SDS, 2\% (wt/vol) PVP-40

$50 \mathrm{mM}$ Tris ( $\mathrm{pH} 8$ ), $150 \mathrm{mM} \mathrm{NaCl}, 1 \%$ (wt/vol) Tween 20, 2\% (wt/vol) PVP-40
$10 \mathrm{mM}$ Tris $(\mathrm{pH} 8.0), 0.1 \% \quad 5$

(vol/vol) Tween 20

$10 \mathrm{mM}$ Tris $(\mathrm{pH} 8.0), 0.1 \% \quad 5$

(vol/vol) Tween 20

$10 \mathrm{mM}$ Tris $(\mathrm{pH} 8.0), 0.1 \% \quad 24$ (vol/vol) Tween 20

$10 \mathrm{mM}$ Tris $(\mathrm{pH} 8.0), 8 \mathrm{mM} 11$ $\mathrm{MgCl}_{2}$

Water

$10 \mathrm{mM}$ Tris $(\mathrm{pH} 8.0), 0.1 \% \quad 5$ (vol/vol) Tween 20

Water

$10 \mathrm{mM}$ Tris (pH 8.0), $0.1 \%$ (vol/vol) Tween 20

$10 \mathrm{mM}$ Tris (pH 8.0), 0.1\% (vol/vol) Tween 20

$10 \mathrm{mM}$ Tris ( $\mathrm{pH} 8.0), 0.1 \%$ (vol/vol) Tween 20

$10 \mathrm{mM}$ Tris ( $\mathrm{pH} 8.0), 0.1 \% \quad 5$

(vol/vol) Tween 20

$10 \mathrm{mM}$ Tris ( $\mathrm{pH} 8.0)$

$10 \mathrm{mM}$ Tris ( $\mathrm{pH} 8.0), 0.1 \%$ (vol/vol) Tween 20

$10 \mathrm{mM}$ Tris ( $\mathrm{pH}$ 8.0)

$10 \mathrm{mM}$ Tris ( $\mathrm{pH} 8.0), 0.1 \%$ (vol/vol) Tween 20

$10 \mathrm{mM}$ Tris (pH 8.0), 0.1\% 15

(vol/vol) Tween 20

$10 \mathrm{mM}$ Tris (pH 8.0)

Data not shown

$10 \mathrm{mM}$ Tris $(\mathrm{pH} 8.0), 0.1 \% \quad 5$ (vol/vol) Tween 20

The table lists organisms and the lysis and wash buffers used by us or other research groups in conjunction with the rapid cellulose filter based nucleic acid purification method using either the dipstick or filter discs. 
The dipstick purification method is a radically different approach to traditional methodologies because it is designed for simplicity and speed over yield; thus, the common parameters used to compare nucleic acid purification systems such as DNA/RNA isolation efficiency or total yields are not suitable. More appropriate performance measures are the time, cost and resources required to purify nucleic acids and the target sensitivity it imparts on the DNA amplification reaction. Furthermore, it is not possible to calculate a single value for the nucleic acid extraction efficiency of the dipsticks because it is dependent on the volume absorbed by the dipsticks, the amount of nucleic acid available for capture, the composition of the extract and its effects on nucleic acid interaction with the cellulose. In a previous study, we estimated that the technology is capable of purifying $\geq 51 \%$ of nucleic acids from samples ${ }^{5}$, although its ability to purify trace quantities of template (12 genomic copies) from an extract ${ }^{11}$ is a better indicator of the dipstick's capabilities.

The rapid (30-s) sample processing of the dipstick purification method enables users to process large numbers of samples quickly with minimal effort, making it ideal for high-throughput nucleic acid purification, including molecular diagnostics for disease detection, genotype screening and heterozygosity testing ${ }^{12-14}$. In addition, the accessibility of the raw materials-that is, cellulose-based filter paper and wax - and the low cost of each dipstick ( $<\$ 0.02$ USD), makes performing molecular diagnostic assays with this technology achievable in limited-resource settings, including university and high school classrooms, field-based environments, urban environments (e.g., airports) and developing countries.

\section{Application of the method}

We have successfully used this technology to rapidly purify genomic DNA from a wide range of sample sources, including human blood samples and melanoma cell lines, as well as from important agricultural crop species such as wheat, sugar cane, tomato, barely, sorghum, soybean, rice and citrus $^{5}$. We have also demonstrated its ability to purify detectable levels of fungal (Fusarium oxysporum), bacterial (Pseudomonas syringae) and RNA-based viral pathogens (Cucumber mosaic virus) from infected plants, as well as bacterial pathogens (Actinobacillus pleuropneumoniae) from pig lung swabs and the human pathogens Campylobacter jejuni and Campylobacter coli on ready-to-sell processed chicken meat ${ }^{5,6,11}$. The ability of the method to detect organisms from diverse taxonomic domains and kingdoms, as well as an RNA virus, suggests that the dipsticks are capable of purifying nucleic acids from any organism, provided an appropriate buffer system can be established.

Since its publication, the rapid purification of nucleic acids with cellulose filters has now been incorporated into a wide variety of assays. An up-to-date list of all the reported applications of our rapid nucleic acid purification method has been compiled, including the target organism and buffer systems used (Table 1). The dipstick purification method provides advantages for a number of common research applications. First, the dipsticks are ideal for routine laboratory diagnostic testing, such as high-throughput genotyping, in which a large number of biological samples need to be tested for the presence of specific genetic markers. The method can be considered high throughput because the dipsticks make it possible to process enough samples to fill a standard 96-well PCR machine within $\sim 1 \mathrm{~h}$. Consistent with this, the dipsticks have been used for the biological barcoding of crayfish $^{13}$. Second, the dipstick's ability to rapidly process a sample from raw tissue through to elution of nucleic acids into a DNA amplification reaction-without any pipetting or equipment-is ideal for point-of-need (PON) applications. PON diagnostics are performed on site (e.g., farm, field, remote locations) to avoid the delays and logistics involved in transporting samples back to central laboratories for testing and thus greatly benefit from minimalist approaches. As such, a number of research groups have adopted the dipstick purification method for PON diagnostic applications, including rapid diagnostics for important crop diseases (Phytophthora capsica ${ }^{15}$ and Magnaporthe oryzae (rice blast $)^{16}$ ), and a field-deployable diagnostic for white spot syndrome virus in shrimp ${ }^{14}$. Third, the dipsticks are ideal for educational purposes in high school or university science classes because they are affordable, made from readily available materials and do not require extensive technical skills to perform purifications. As such, the dipstick method will probably encourage a greater adoption of molecular biology into educational programs.

In the midst of the current SARS-CoV-2 (COVID-19) pandemic, a potential application of the dipstick technology is to expand the capability of diagnostic deployment to non-laboratory environments such as airports, remote test centers, and general practitioner clinics. Nucleic acid purification from patient samples is generally achieved using expensive commercial kits that require multistep procedures and specialized laboratory equipment. The dipsticks could enable the rapid 
purification of the viral RNA from patient swabs and elute it directly into an amplification mix, where it could be reverse-transcribed and amplified. Single-step reverse transcription loop-mediated isothermal amplification (RT-LAMP) assays have already been demonstrated to be capable of detecting SARS-CoV-2-infected patient samples in $20 \mathrm{~min}$ with a limit of detection as low as 100 copies of the virus, without cross-reactivity with other coronaviruses ${ }^{17,18}$. Although issues such as user safety and assay validation need to be addressed, a rapid, on-site dipstick-based assay for SARS$\mathrm{CoV}-2$ could enable faster identification and isolation of positive patients, which would help to reduce the spread of the disease.

The main disadvantage of the technology is that the dipsticks purify relatively small amounts of nucleic acids, which is insufficient for a number of molecular applications, such as restriction enzyme digests or PCR amplicon clean up. Thus, dipsticks are not suitable for general-purpose nucleic acid purification applications but rather are best suited to amplification-based applications, such as molecular diagnostics, in which their simplicity, low cost and speed provide substantial advantages over current methods.

\section{Comparison with other methods}

There are four key features of the dipstick methodology that sets it apart from other DNA purification methods: (i) it reduces the complicated process of nucleic acid purification to three simple steps, (ii) it does not require any specialized equipment (e.g., pipettes or centrifuges), (iii) it uses low-cost and easily accessible materials, and (iv) consistently sized dipsticks can be easily and quickly manufactured in bulk. By focusing on speed and simplicity, as opposed to yield, we have created a nucleic acid purification system that is specifically targeted to diagnostic applications and can support high-throughput applications, even in low-resource environments.

Commercially available nucleic acid purification methodologies typically involve capturing nucleic acids in the presence of high concentrations of chaotropic salts (e.g., paramagnetic beads or spin columns) and, in comparison to dipstick purifications, are more expensive and more time consuming. They require several pipetting steps and, in the case of spin columns, require the use of centrifuges ${ }^{5,7,8}$. Adaptions of these technologies have been developed using a variety of nucleic acid binding substrates, including diatomaceous earth ${ }^{9}$, aluminum oxide ${ }^{10}$ and fusion- 5 filters ${ }^{19}$, but again, these adaptions are more complicated to set up and require several pipetting steps, making them less practical for high-throughput or remote field applications. The Flinders Technology Associates (FTA) cards (GE Healthcare) use cellulose filter paper impregnated with various chemicals to help lyse cellular membranes from samples such as blood and crushed plant leaves and protect the released DNA from degradation. However, these differ from the dipsticks in that they are designed for medium to long-term storage of the captured DNA and when used as a nucleic acid purification tool require several pipetting and wash steps to elute the $\mathrm{DNA}^{20}$.

A number of research groups have developed 'all-in-one' diagnostic platforms with on-board systems to extract DNA from crude extracts, perform DNA amplification and detect the presence of amplicons $^{21-23}$. This is an attractive concept because it enables users with limited scientific skills to perform diagnostic assays. However, these systems are composed of a large number of components required to move liquids within the device and perform the different processes. As such, these devices are relatively time consuming to assemble and difficult to produce at scale without a sizable commercial investment. By contrast, the dipsticks can be easily manufactured at scale and require only a few components (filter paper, wax and a pasta maker). The simplicity of the dipstick manufacturing process and the low-cost and accessibility of the required materials is a substantial advantage of this technology that can benefit users in modern research laboratories as well as low-resource facilities (e.g., developing countries, high schools, and small university teaching lab). The cost of diagnostics is an important limiting factor for industry and governments; therefore, technologies such as the dipstick purification system-which that can deliver accurate results for a low cost-are highly desirable.

Before the development of the dipstick, we had demonstrated that the nucleic acid purification could be achieved using a 3-mm-diameter disc of Whatman filter paper ${ }^{5}$. The filter disc method works by the same process as the dipsticks but is slower because the solutions need to be pipetted on and off the paper disc, or the disc must be moved between solutions. Since the publication this method, some research groups have adopted the paper disc method by incorporating the discs into a pipette tip so that liquids could be more efficiently pipetted on and off the filter disc ${ }^{12,24}$ or into a recycled spin column ${ }^{25}$. Although the core technology is the same, we find that the dipstick format is 
less laborious to manufacture in large scale and does not require the use of pipettors, making the dipstick method more suitable to high-throughput applications and low-resource environments.

Successful amplification using direct PCR or direct LAMP, in which small volumes of unprocessed sample are added to the DNA amplification reactions, has demonstrated that some sample types do not require processing before amplification ${ }^{26,27}$. These methods do not involve nucleic acid purification but rather rely on the capability of DNA polymerases to tolerate low levels of contaminants in the reactions ${ }^{28}$. By contrast, the dipstick method presented here actively removes DNA amplification inhibitors before elution, as demonstrated in experiments in which samples added directly into DNA amplification reactions failed to amplify, whereas dipstick purifications from the same samples resulted in the successful amplification ${ }^{5}$. Although additional processing steps, such as centrifugation or sample dilution, might extend the number of sources that can be used for direct PCR/LAMP, such a method would be more complicated and time consuming than the dipstick approach. As noted by the original inventors of direct $\mathrm{PCR}^{27}$, without purification, direct sample addition into amplification reactions can lead to inhibition of the DNA polymerase. Thus, the advantage of the dipstick method over direct sample addition is that the purification process enriches the amount of nucleic acids relative to contaminants, resulting in greater sensitivity and reliability.

\section{Experimental design}

Nucleic acid release from samples

The technique reported here should be applicable to the purification of nucleic acids from any organism, but some development work will be necessary for different organisms and sample types. The first step in the method is the homogenization and lysis of the tissue in an extraction buffer. Optimization of the extraction buffer might be needed to ensure that the nucleic acids are released and inhibitory compounds from either the extract or the buffers are neutralized, diluted or eliminated. Although we have developed cell lysis methods for different organisms and sample types (Table 1), no a priori method exists that will work for all types of samples. A good starting point is to use the lysis buffers that have already been developed for similar tissues/organisms of interest (Table 1) and adapt them for the dipstick purification system. The dipstick purification method has been shown to work well with many commonly used extraction buffer components, including SDS, guanidine hydrochloride, Tween 20 , and proteinase $\mathrm{K}^{5,11,13,24}$. We have found that an extraction buffer containing: $20 \mathrm{mM}$ Tris (pH 8), $25 \mathrm{mM} \mathrm{NaCl}, 2.5 \mathrm{mM}$ EDTA, 0.05\% (wt/vol) SDS, and $2 \%$ (wt/vol) PVP-40 works well with many samples.

When developing a cell lysis method for the dipstick purification system, it is important to gain an understanding of the concentration range of the target organism relative to the concentrations of compounds that are inhibitory to DNA amplification within the samples to be assayed. We have found that, in most cases, nucleic acid release can be achieved in a single step in which the tissue is macerated or mixed into a cell lysis buffer; for example, nucleic acid release from plant leaves can be achieved by briefly shaking the plant leaves in a tube with extraction buffer and ball bearings, as demonstrated in the supplemental movie of the original dipstick publication ${ }^{5}$. Recently, we discovered that nucleic acids can be released from plant leaves with less effort by placing a small leaf segment $(\sim 10 \times 10 \mathrm{~mm})$ into a small Ziploc plastic bag with $2 \mathrm{ml}$ extraction buffer and briefly mashing the tissue with fingers (M.G.M., data not shown). Ziploc bags are cheap, light and easy to transport and can be discarded after use, preventing cross-sample contamination. The traditional cell disruption technique of grinding of samples with a mortar and pestle is slow and highly laborious and is not required for most dipstick purification applications. Thus, in most cases, the dipsticks enable the users to purify nucleic acids from raw samples and elute them into the DNA amplification reaction within $30 \mathrm{~s}$, including the cell lysis step.

For some sample types, nucleic acid release cannot be achieved in a single step; these include samples that contain trace levels of the target organism and may require centrifugation ${ }^{11}$, samples containing high levels of inhibitory compounds or samples containing infectious agents that need to be inactivated before processing. Nucleic acid purification from these samples will thus take longer than $30 \mathrm{~s}$, with the timing dependent on the amount of sample processing required. Compounds in the sample that can inhibit the DNA amplification reaction can be neutralized or diluted by the lysis buffer or eliminated through techniques such as enzymatic treatment (e.g., proteinase $\mathrm{K}$ ) or centrifugation $^{11}$. 
a

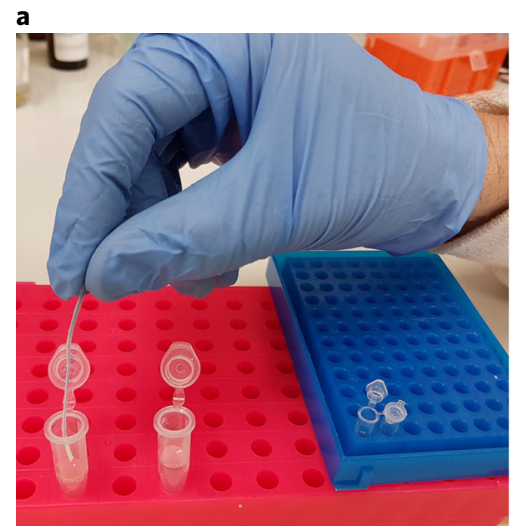

b

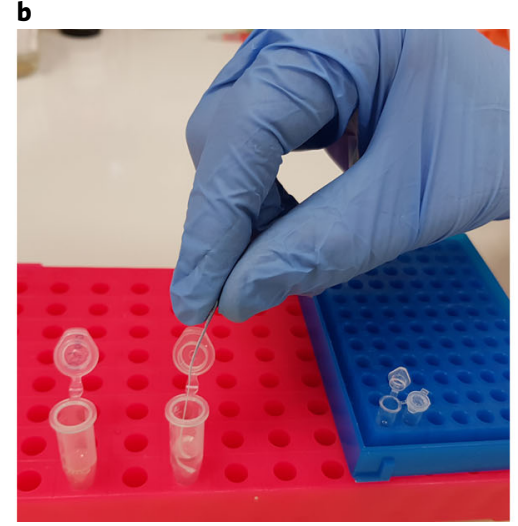

c

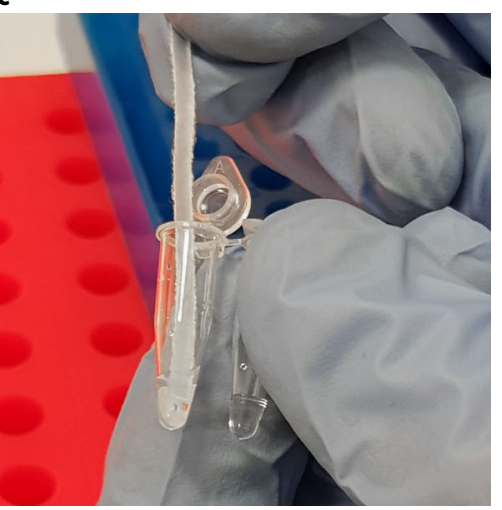

Fig. 2 | Rapid nucleic acid purification using dipsticks. a, Nucleic acids are captured by dipping the dipstick into the sample until the nucleic acid binding zone of the dipstick is saturated with solution. b, Contaminating compounds are removed by dipping 5 times into the wash buffer. c, Nucleic acids are eluted by dipping 15 times directly into the amplification reaction.

Nucleic acid purification using dipsticks

Once the nucleic acids are in solution, they can be rapidly purified using the dipsticks in three rapid steps (Fig. 2, Supplementary Video 1). First, the dipsticks are dipped into the sample extract to capture the nucleic acids (Fig. 2a). A typical size dipstick with a capture area of $2 \times 6 \mathrm{~mm}$ will absorb approximately $2-4 \mu \mathrm{l}$ of sample and will capture the nucleic acids present in this volume. The exact volume of the sample taken up by the dipstick is directly proportional to the area of its nucleic acid binding zone; thus, the size of this zone should be adjusted to best suit the application.

Second, the dipsticks are dipped into a wash solution to remove contaminants from the sample that can inhibit the DNA amplification reaction (Fig. 2b). We have found that dipping the dipstick five times into $10 \mathrm{mM}$ Tris $(\mathrm{pH} 8)$ is ideal for most applications. However, for sample extracts with high amounts of contaminants, increasing the number of dips into the wash buffer can help improve the reliability of the assay. In addition, inclusion of magnesium chloride in the wash buffer can prevent dilution of the magnesium ion concentration in the amplification reaction and may also help to neutralize the effects of contaminating ions (e.g., $\mathrm{Ca}^{2+}$ ) from the sample ${ }^{11,29}$.

Third, the dipstick is dipped directly into the amplification reaction to elute the nucleic acids (Fig. 2c). We have found that dipping the dipsticks into the amplification reaction 15 times gives the nucleic acids a sufficient amount of time to release from the dipsticks. For best results, we maximize liquid movement through the dipstick by pushing the nucleic acid binding zone of the dipstick into the bottom of the tube with each dip to encourage nucleic acid release (Fig. 2c). Upon completion, the dipstick can be discarded, and the DNA amplification reaction is ready to run. Dipstick purification has been successfully used in combination with PCR and isothermal (LAMP, RPA) DNA amplification technologies 5 .

\section{Limitations}

Unlike commonly used solid-phase nucleic acid techniques such as silica spin columns or paramagnetic beads, the dipstick purification method does not substantially concentrate the nucleic acids in the sample. The dipsticks purify nucleic acids from the small volume of sample that is absorbed by the cellulose fibers. Thus, the target nucleic acids must be at a sufficient concentration in the sample to enable detection by DNA amplification. However, dipsticks can be used to amplify trace amounts of nucleic acids; we have detected as low as 12 copies of Campylobacter spp. genome (verified by standard culture-based cell counts on the same samples) using dipstick technology in combination with LAMP amplification ${ }^{11}$. In addition, the small capture volume of the dipsticks makes them unsuitable for purifying large quantities of nucleic acids. The dipstick system is designed to considerably enhance speed and simplify the purification process; thus, if multiple DNA amplification reactions are required from a sample, individual dipstick purifications will be required, each taking an additional $30 \mathrm{~s}$ each to perform. 


\section{Biological materials}

- Pseudomonas syringae pv. tomato strain DC3000 (American Type Culture Collection (ATCC), cat. no. BAA-871) $\triangle$ CRITICAL Pseudomonas syringae pv. tomato strain DC3000 was donated by Y. Trusov (University of Queensland) and was grown overnight at $28{ }^{\circ} \mathrm{C}$ in lysogeny broth (LB) liquid medium containing $50 \mathrm{mg} / \mathrm{l}$ kanamycin.

\section{Reagents}

- Paraplast Plus (Sigma-Aldrich, cat. no. P3683)

- Navy blue candle-making dye chips (Essential Candle Supply, product code DCNB)

- Guanidine hydrochloride (Sigma-Aldrich, cat. no. G3272) ! CAUTION Guanidine hydrochloride is harmful if swallowed or inhaled, and causes skin and eye irritation. Wear protective gloves and eye protection when handling.

- Triton X-100 (Sigma-Aldrich, cat. no. T9284) ! CAUTION Triton X100 causes serious eye irritation. Protective gloves and eye protection should be used when handling.

- Proteinase K (New England BioLabs, cat. no. P8107S)

- Magnesium chloride $\left(\mathrm{MgCl}_{2}\right.$; Chem-supply, cat. no. MA029)

- Hydrochloric acid (HCl) (Merck-Milipore, cat. no. 1.00319.2511) ! CAUTION Hydrochloric acid is highly corrosive and can cause severe skin burns and eye damage. Protective clothing, gloves and eye protection should be used when handling.

- Polyvinylpyrrolidone (PVP-40; average mol. wt. = 40,000; Sigma-Aldrich, cat. no. PVP40)

- Tris base (Sigma-Aldrich, cat. no. T1503)

- Ethylenediaminetetraacetic acid (EDTA; Sigma-Aldrich, cat. no. E9884) ! CAUTION Ethylenediaminetetraacetic acid causes serious eye irritation; eye protection should be used when handling.

- Tween 20 (Sigma-Aldrich, cat. no. P9416)

- Sodium chloride (NaCl; Sigma-Aldrich, cat. no. S9888)

- Sodium dodecyl sulfate (SDS; Sigma-Aldrich, cat. no. L3771) ! CAUTION Sodium dodecyl sulfate is a flammable solid. It is harmful if swallowed, causes skin irritation and serious eye damage, and can cause respiratory irritation. Protective gloves and eye protection should be used when handling.

- Tryptone (Oxoid, cat. no. LP0042)

- Yeast extract (Merck, cat. no. 103753)

- Kanamycin monosulfate (PhytoTech Labs, cat. no. K378)

- QuantiFluor ONE dsDNA System (Promega, cat. no. E4870)

- $2 \times$ GoTaq qPCR Master Mix (Promega, cat. no. A6002)

-10× ThermoPol Reaction Buffer (New England BioLabs, cat. no. B9004S)

Oligonucleotides $\left(5^{\prime}-3^{\prime}\right)$

- $P$. syringae forward primer: TACGACTCAGCGCCGACGAGAA (Integrated DNA Technologies, custom order)

- P. syringae reverse primer: TTCGTGGCCATGCCAGACAG (Integrated DNA Technologies, custom order)

\section{Equipment}

- Whatman grade 1 filter paper $100 \times 75$-mm sheets (GE Healthcare, cat. no.1001-824)

- Colored A4 photocopy paper (e.g., Optix Suni yellow paper; Australian Paper, cat. no. 193363)

- Benchtop gas bottle

- Bunsen burner

- Pasta maker machine. We use a low-cost, unbranded pasta maker purchased through Ebay that is equivalent to an Avanti pasta maker machine (Avanti, cat. no. 26812). However, any brand of pasta maker should work $\triangle$ CRITICAL Ensure that the pasta maker has a cutter that can make 2-mm-wide strips and is manually operated.

- Stainless-steel scissors

- Mechanical pencil

- Ruler

- Microcentrifuge tubes (1.5 ml; SSI; LabGear Australia, cat. no. SSIB1210)

- Glass flask (250 ml)

- Square Petri dish $(120 \times 120 \mathrm{~mm}$; Greiner Bio-One, cat. no. 688102) 
- Household aluminum foil

- MyGo Mini qPCR system (IT-IS Life Science)

- Fluorometer (Quantus; Promega)

\section{Reagent setup}

\section{Extraction buffer}

Prepare 1 liter of extraction buffer (20 mM Tris ( $\mathrm{pH}$ 8), $25 \mathrm{mM} \mathrm{NaCl}, 2.5 \mathrm{mM}$ EDTA, 0.05\% (wt/vol) SDS, 2\% (wt/vol) PVP-40) by dissolving $2.42 \mathrm{~g}$ of Tris base, $1.46 \mathrm{~g} \mathrm{NaCl}$, and $20 \mathrm{~g} \mathrm{PVP}-40 \mathrm{in} \sim 900 \mathrm{ml}$ of water. Add $5 \mathrm{ml}$ of EDTA (pH 8.0, $500 \mathrm{mM}$ ) and $5 \mathrm{ml} \mathrm{SDS}(10 \%$ (wt/vol)). Adjust the $\mathrm{pH}$ to 8 with $\mathrm{HCl}$ and make the volume up to 1 liter with water. The extraction buffer does not need to be sterilized and can be stored at room temperature $\left(18-25^{\circ} \mathrm{C}\right)$ for at least 1 year.

\section{Dipstick wash buffer}

Prepare 1 liter of dipstick wash buffer (10 mM Tris ( $\mathrm{pH} 8)$ ) by dissolving $1.21 \mathrm{~g}$ of Tris base in $\sim 900$ $\mathrm{ml}$ of water. Adjust the $\mathrm{pH}$ to 8 with $\mathrm{HCl}$ and make the volume up to 1 liter with water. The dipstick wash buffer does not need to be sterilized and can be stored at room temperature for at least 1 year. $\triangle$ CRITICAL In the original dipstick publication, $10 \mathrm{mM}$ Tris ( $\mathrm{pH} \mathrm{8.0),} \mathrm{0.1 \%} \mathrm{(vol/vol)} \mathrm{Tween} 20$ was used as the wash buffer. Since then, we have found that the Tween 20 can negatively interfere with DNA amplification reactions, and thus we recommend removing it from the wash buffer.

\section{QPCR reaction}

A master mix of the qPCR reaction should be prepared so that each $25 \mu$ qPCR reaction is composed of $12.5 \mu \mathrm{l}$ of $2 \times$ GoTaq qPCR Master Mix, $0.75 \mu \mathrm{l}$ of $10 \mu \mathrm{M}$ P. syringae forward and reverse primers (300 $\mathrm{nM}$ each) and $11.75 \mu \mathrm{l}$ of water. The reaction should be made up fresh.

\section{1× PCR buffer}

Dilute $100 \mu \mathrm{l} 10 \times$ ThermoPol Reaction Buffer in $900 \mu \mathrm{l}$ of water. The $1 \times$ PCR buffer is made up fresh.

\section{Lysogeny broth liquid medium}

Lysogeny broth (LB) medium is prepared by dissolving $10 \mathrm{~g}$ tryptone, $5 \mathrm{~g}$ of yeast extract and $10 \mathrm{~g}$ of $\mathrm{NaCl}$ in water and bringing the volume up to 1 liter. The medium is autoclaved at $121^{\circ} \mathrm{C}$ for $20 \mathrm{~min}$ and allowed to cool. Sterile LB medium can be stored at room temperature for at least 1 year. In a laminar flow hood, add $100 \mu \mathrm{l}$ of $50 \mathrm{mg} / \mathrm{ml}$ kanamycin monosulfate (in water) to $100 \mathrm{ml}$ of $\mathrm{LB}$ medium. The kanamycin-containing LB medium can be stored at $4{ }^{\circ} \mathrm{C}$ for up to 2 weeks. A 5 -ml aliquot of LB medium containing kanamycin is used to culture $P$. syringae.

\section{Procedure}

Producing dipstick blanks Timing 20 min

1 Combine $95 \mathrm{~g}$ of Paraplast Plus wax chips with a 0.67 -g block of colored candle-making dye in a glass flask (Fig. 3a, Supplementary Video 2).

2 Heat the wax over a Bunsen burner or hot plate until all the wax has melted.

! CAUTION Paraffin wax is flammable and should be kept out of direct contact with flames.

3 Pour the wax into a disposable $120 \times 120$-mm plastic Petri dish.

4 Holding the $75 \times 100$-mm cellulose filter sheet by the top two corners (along its long edge), lower the sheet into the wax, starting from the bottom and allowing the wax to impregnate the filter paper. (Fig. 3b).

\section{? TROUBLESHOOTING}

5 Once approximately two-thirds of the cellulose filter is submerged in the wax, allow the wax to wick up the filter paper by capillary action so that it forms a straight line parallel with the top of the paper, leaving $\sim 20 \mathrm{~mm}$ of paper uncovered.

\section{? TROUBLESHOOTING}

6 When removing the filter paper from the wax, wipe it along the side of the Petri dish to remove excess wax (Fig. 3c).

7 Set the wax-soaked filter paper on aluminum foil to allow the wax to harden for at least $1 \mathrm{~min}$. PAUSE POINT Large numbers of dipstick blanks can be prepared at one time and stored until needed. The uncut dipstick blanks can be stored indefinitely in a in a sealed container at room temperature. 

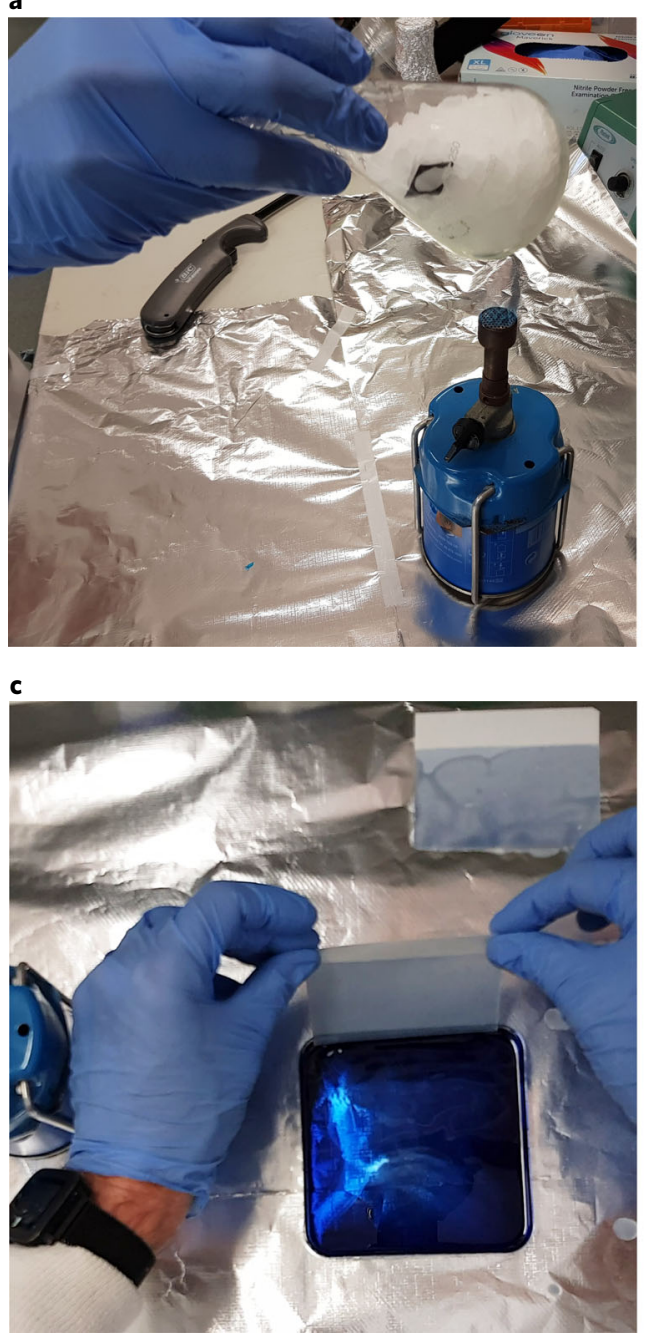

b

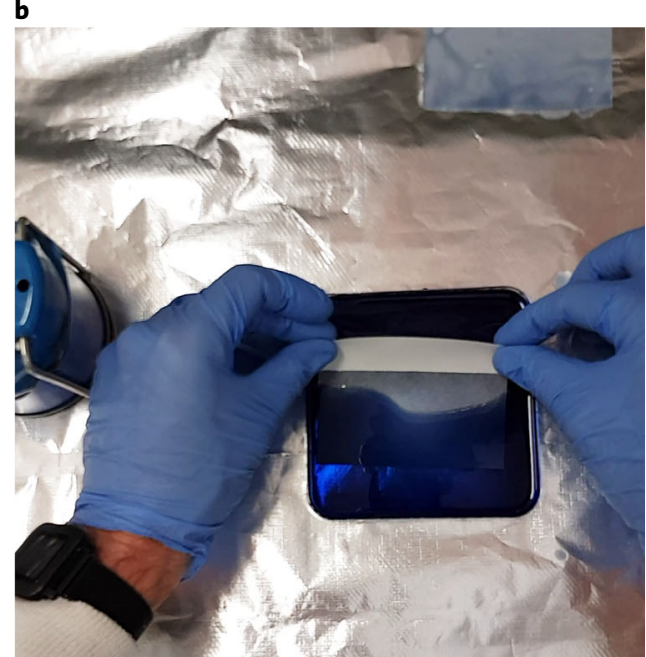

d

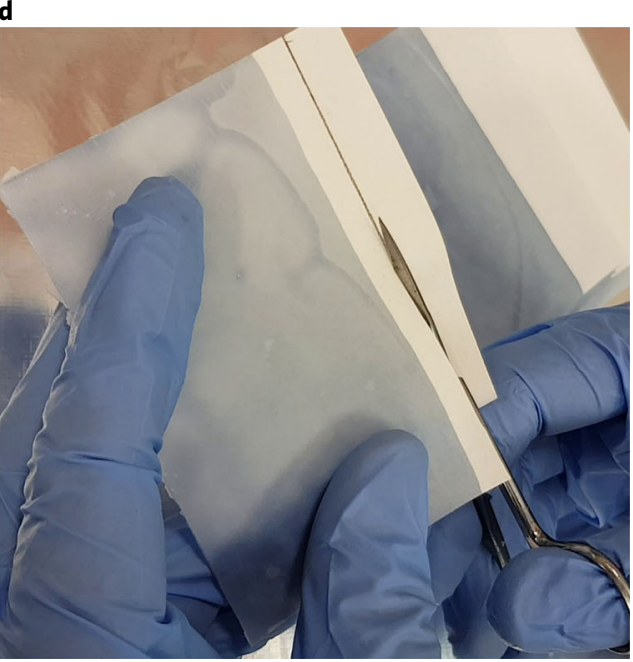

Fig. 3 I Preparation of the dipstick blanks. a, The wax is melted with a colored dye to make identification of the nucleic acid binding zone easier. $\mathbf{b}$. The molten wax is infused into the cellulose filter paper up to $\sim 20 \mathrm{~mm}$ from the end to create the dipstick blank. c, Excess wax is removed from the dipstick blank by wiping on the edge of the Petri dish. d, A pencil line is drawn on the dipstick blank to the desired length of the nucleic acid binding zone and the excess filter paper is cut away.

8 Draw a pencil line parallel to the wax edge across the unwaxed portion $6 \mathrm{~mm}$ away from the wax edge (Fig. 3d). This line sets the length of the nucleic acid binding area on the dipstick.

$\triangle$ CRITICAL STEP Wear gloves, work on a clean surface and use a pencil, ruler and scissors that are free from DNA and RNA contamination.

9 Using clean scissors, cut inside of the pencil line to create a blank that has a 6-mm-wide unwaxed portion (Fig. 3d). The waxed portion to be used as a handle will be approximately $50 \mathrm{~mm}$.

- PAUSE POINT Typically, the trimmed dipstick blanks are immediately processed to create individual dipsticks. However, they can be stored indefinitely in a sealed container at room temperature.

\section{Producing the dipsticks from the blanks Timing $\mathbf{2}$ min}

10 Fold a $105 \times 50-\mathrm{mm}$ sheet of colored photocopy paper in half along its long axis to create a $105 \times 25-\mathrm{mm}$ folded sheet (Supplementary Video 2).

11 Place the folded sheet of colored paper into the pasta maker, with the folded edge against the 2-mm-wide cutters and the open edge up. 

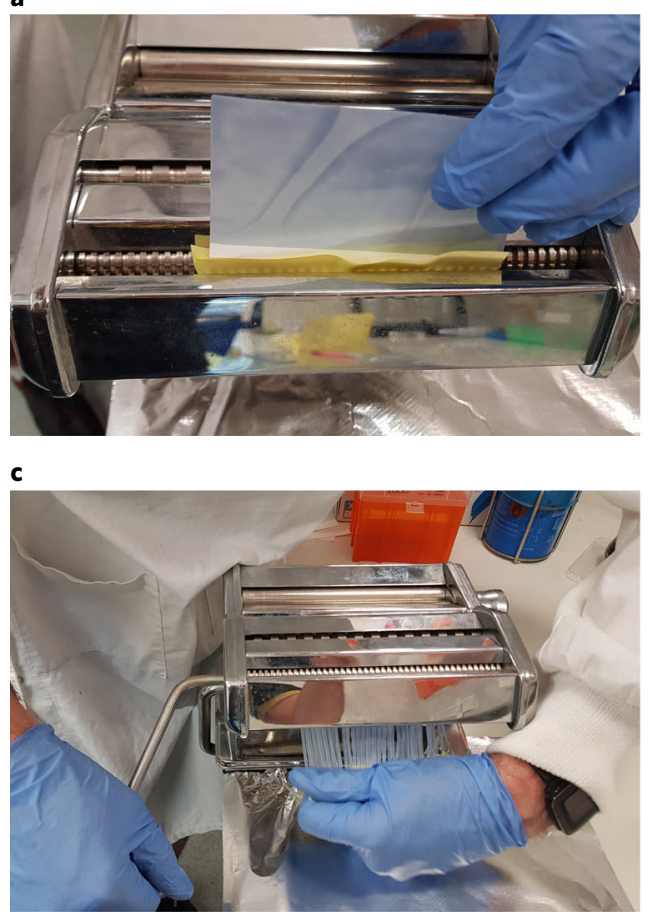

b

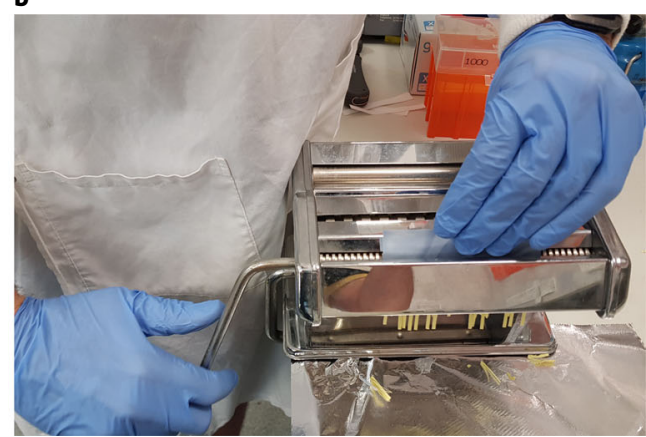

d

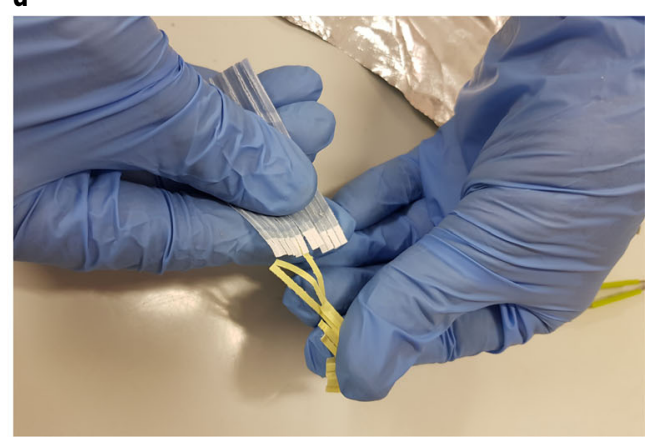

Fig. 4 | Rapid manufacture of dipsticks using a pasta maker. a, The dipstick blank is placed between the edges of a folded sheet of colored paper that has been inserted into the pasta maker. $\mathbf{b}$, The dipstick blank is guided through the pasta maker. c, The dipsticks are gently pulled out from the pasta maker as they are being cut. d, The dipsticks are bent to release the colored paper, which can then be pulled away from the dipsticks.

12 Hold the colored paper in one hand while turning the handle of the pasta maker with the other hand to engage the paper in the cutting wheels.

13 Place the unwaxed portion of the dipstick blank between the two edges of the folded sheet of colored paper that has been inserted into the pasta maker. (Fig. 4a).

14 Hold the dipstick blank in one hand while slowly turning the handle of the pasta maker with the other hand (Fig. 4b).

? TROUBLESHOOTING

15 When the cut dipsticks have protruded from the underside of the pasta cutter by $\sim 30-40 \mathrm{~mm}$, gently pull down on them with one hand while continuing to turn the handle with the other to help guide them out of the cutter (Fig. 4c).

16 Once they are fully released from the pasta maker, gently bend the dipsticks to allow the colored paper to peel away from the dipsticks so that it can be easily removed (Fig. 4d).

PAUSE POINT Large numbers of dipsticks can be prepared and stored indefinitely until needed. They should be stored in a sealed container at room temperature to prevent possible contaminants in the air from settling on them.

\section{? TROUBLESHOOTING}

\section{Reagent preparation Timing $10 \mathrm{~min}$}

17 Before sample processing, prepare extraction buffer, wash buffer and DNA amplification reaction mix and divide the reagents into aliquots (typically, 1.5- $\mathrm{ml}$ tubes are used for extraction and wash buffers, and a 0.2-ml tube is used for the DNA amplification reaction mix); one set is needed for each sample to be processed.

PAUSE POINT Large numbers of extraction and wash buffer aliquots can be prepared in advance and can be stored for at least 1 year at room temperature until needed. Typically, the DNA amplification reactions will be prepared within $<3 \mathrm{~h}$ of dipstick purification and kept at or $\leq 4{ }^{\circ} \mathrm{C}$ until required. However, DNA amplification reactions can be lyophilized and stored for at least 1 year at room temperature if cold storage is not practical $^{30}$. 


\section{Sample preparation and cell lysis Timing $10 \mathrm{~s}$ to $\mathbf{3 0} \mathrm{min}$}

18 Release nucleic acids from the tissue.

$\triangle$ CRITICAL STEP The release of the target nucleic acid into solution needs to be optimized for each tissue type. In most cases, maceration of the tissue in cell lysis buffer can be accomplished in a single step. For example, some tissues, such as plant leaves, can often be macerated by shaking in a tube with extraction buffer and ball bearings for $10 \mathrm{~s}$.

\section{Nucleic acid purification using the dipsticks Timing $<30 \mathrm{~s}$}

19 Capture nucleic acids by dipping the dipstick into the sample until the nucleic acid binding zone is completely soaked ( 5 s) (Fig. 2a, Supplementary Video 1).

20 Gently dip the dipstick into $800 \mu \mathrm{l}$ wash buffer five times ( $5 \mathrm{~s}$ total).

$\triangle$ CRITICAL STEP After completion of the wash step, wipe the dipstick on the edge of the wash tube to ensure there are no large droplets of wash buffer remaining on the dipstick (Fig. 2b, Supplementary Video 1).

21 Dip the dipstick into $20-50 \mu \mathrm{l}$ DNA amplification reaction mix 15 times ( 10 s total) (Fig. $2 c$, Supplementary Video 1).

$\triangle$ CRITICAL STEP Maximize the elution of nucleic acids from the dipstick by encouraging liquid movement through the nucleic acid binding zone of the dipstick by pushing the dipstick into the bottom of the tube with each dip, causing the cellulose to bend and compress.

\section{? TROUBLESHOOTING}

22 After elution, wipe the dipstick on the edge of the amplification tube to ensure there are no large droplets of DNA amplification reaction mix remaining on the dipstick.

\section{DNA amplification Timing 30-120 min}

23 Perform the DNA amplification reaction per standard protocol ${ }^{5}$ (30-60 min, isothermal amplification; 1-2 h, PCR).

\section{? TROUBLESHOOTING}

\section{Troubleshooting}

Troubleshooting advice can be found in Table 2 .

Table 2 | Troubleshooting table

Step Problem

4

Wax does not wick through the Wax is too cold paper smoothly

5 Wax does not form a straight edge along the top of the filter paper

14 Dipstick blanks do not move easily through the pasta maker Dipstick blanks twist while moving through the pasta maker

Dipstick blank will not move through the pasta maker

16 The colored paper does not easily peel off the dipsticks

The pasta maker is not cutting the dipsticks

Possible reason Solution

The wax should be poured back into the glass flask and reheated before reusing it

Wax is too cold or the dipstick blank was not given sufficient time to form a straight edge

Dipstick blanks have excessive amounts of wax on their surface Uneven pressure applied to the dipstick blank

Cutting wheels slipping on the wax

The colored paper is strongly attached to the wax of the dipsticks

The blades of the pasta machine are becoming blunt
Use hot wax that wicks quickly through the paper. When approximately two-thirds of the filter paper is submerged in the wax, slow down and allow the wax to wick up through the filter paper by capillary action

Hold a razor blade perpendicular to the dipstick blank and gently scape across the large deposit of wax to reduce the amount of wax Gently pulling back on either corner of the dipstick blank as it is pulled through the pasta maker can be used to prevent it from twisting and creating dipsticks with curved handles

Clean the pasta maker cutting wheels with paper towel soaked in ethanol to help remove the wax buildup. Alternatively, use a razor blade to make a series of shallow score marks across the top of both cutting wheels, approximately $1.5 \mathrm{~mm}$ apart, to help them grip the dipstick blank. Help the dipstick blank through the pasta maker by gently pushing the blank from the top while turning the handle Ensure that only a small $(\sim 5-\mathrm{mm})$ section of the waxed portion of the dipstick blanks beyond the unwaxed portion is inserted between the colored paper sheets

Clean the pasta maker cutting wheels with a paper towel soaked in ethanol to help remove the wax. Alternatively, a new pasta maker might be needed

Table continued 
Table 2 (continued)

\begin{tabular}{|c|c|c|c|}
\hline Step & Problem & Possible reason & Solution \\
\hline 21 & $\begin{array}{l}\text { Visible contaminants (e.g., } \\
\text { particulates or coloration) can } \\
\text { be seen in the amplification } \\
\text { reaction }\end{array}$ & $\begin{array}{l}\text { Sample has a high } \\
\text { contaminant load }\end{array}$ & $\begin{array}{l}\text { Use a larger extraction buffer to tissue ratio. In addition, increase the } \\
\text { number of dips of the dipstick into the wash buffer to } 10\end{array}$ \\
\hline 23 & $\begin{array}{l}\text { Amplification reaction fails to } \\
\text { amplify, despite presence of } \\
\text { template in the sample }\end{array}$ & $\begin{array}{l}\text { Inhibitors carried over into the } \\
\text { amplification reaction }\end{array}$ & $\begin{array}{l}\text { Increase the extraction buffer to tissue ratio to reduce the } \\
\text { concentration of inhibitory compounds. In addition, increase the } \\
\text { number of dips of the dipstick in the wash buffer to 10. Change the } \\
\text { composition or the chemical concentrations of the extraction buffer to } \\
\text { prevent chemical carryover from the buffer interfering with the DNA } \\
\text { amplification reaction }\end{array}$ \\
\hline & $\begin{array}{l}\text { Amplification reaction } \\
\text { amplifies poorly }\end{array}$ & $\begin{array}{l}\text { Dilution of the DNA } \\
\text { amplification reaction with } \\
\text { wash buffer }\end{array}$ & $\begin{array}{l}\text { Increase the amount of the DNA amplification reaction to at least } \\
20 \mu \mathrm{l} \text {. After dipping into the wash buffer, wipe the dipstick on the side } \\
\text { of the tube to minimize reagent carryover }\end{array}$ \\
\hline
\end{tabular}

Steps 1-9, production of dipstick blanks: $20 \mathrm{~min}$

Steps 10-16, production of dipsticks from the blanks: 2 min

Step 17, reagent preparation: $10 \mathrm{~min}$

Step 18, sample preparation and cell lysis: $10 \mathrm{~s}$ to $30 \mathrm{~min}$

Steps 19-22, nucleic acid purification using the dipsticks: $<30 \mathrm{~s}$

Step 23, DNA amplification: 30-120 $\mathrm{min}$

\section{Anticipated results}

We added $1,5,10$, or $50 \mu \mathrm{l}$ of an overnight $P$. syringae culture to $500 \mu \mathrm{l}$ of extraction buffer in order to lyse the cells and release their DNA into solution (Supplementary Methods). The concentration of the DNA in each sample was determined using a double-stranded DNA-specific fluorometric assay (QuantiFluor ONE dsDNA System, https://www.promega.com.au/-/media/files/resources/protcards/ quantifluor-one-dsdna-system-quick-protocol.pdf?la=en). As expected, the concentration of DNA in each of the samples was proportional to the amount of culture added (Fig. 5a). The amount of DNA the dipsticks purified from each sample strongly correlated with the concentration of DNA in each sample $\left(r^{2}=0.99\right.$ with Pearson correlation coefficient $\left.r=0.99 ; P<0.05\right)$ (Fig. 5b). These results are consistent with our previous findings that revealed that the dipsticks do not concentrate the nucleic acids within a sample but instead reflect the target concentration in the extract ${ }^{5}$. Furthermore, the low variation in total amount of DNA obtained by dipstick purification from each sample reveals that the dipstick methodology is highly repeatable (Fig. 5b).

Dipstick-purified DNA from these samples was eluted directly into $25-\mu \mathrm{l}$ qPCR reactions with primers designed against the P. syringae genome. Four reactions-using DNA from four separate dipstick purifications-were used for each sample. The analysis revealed correlations between the qPCR quantification values $\left(2^{-\mathrm{Cq}}\right)(\mathrm{Cq}$, quantification cycle) and both the concentration of DNA in each sample $\left(r^{2}=0.96\right.$, with Pearson correlation coefficient $\left.r=0.97 ; P<0.05\right)$ and the amount of dipstick-purified DNA $\left(r^{2}=0.91\right.$, with Pearson correlation coefficient $\left.r=0.96 ; P<0.05\right)$ (Fig. 5c). However, we observed that one of the four DNA purification repeats from the sample containing $50 \mu \mathrm{l}$ of culture failed to produce a quantifiable amplicon. By contrast, all the extractions from the other culture samples (four out of four repeats) produced the expected amplicon. This sample was noticeably more viscous than the other samples, probably because of its high concentration of genomic DNA, and was intentionally added to this experiment to reinforce the need to optimize the sample to buffer ratio for the desired assay. The presence of high quantities of contaminants or nucleic acids because of sample overloading is the most common cause of dipstick purification failure. The experiment shown here demonstrates that reducing the sample to lysis buffer ratio can successfully overcome overloading of the dipsticks and ensure reliable detection of the target organism.

In summary, we have found that our system is a practical solution that supports high-throughput nucleic acid-based diagnostic research. The dipsticks are cheap and easy to manufacture to a consistent size with easily accessible materials (filter paper, wax, and a pasta maker), and the dipstick purification method is fast, with minimal handling steps, enabling large numbers of samples to be processed within a short time frame. 

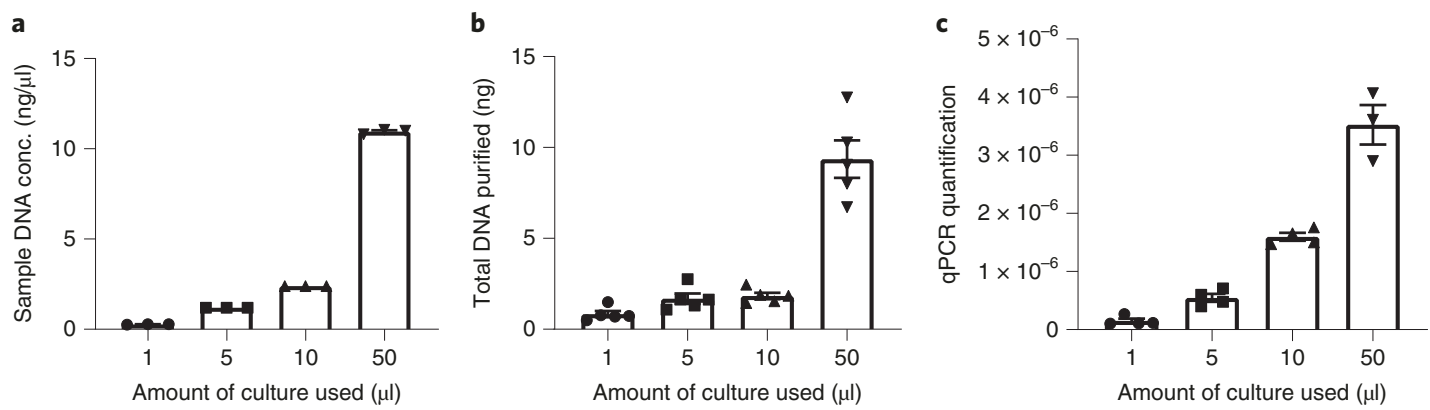

Fig. 5 | Purification and detection of $P$. syringae. Different amounts of $P$. syringae culture (1-50 $\mu \mathrm{l})$ were added to $500 \mu$ l of extraction buffer. a, The concentration of DNA in the initial samples was determined by fluorometric assay in triplicate $(n=3)$. $\mathbf{b}$, Dipsticks were used to purify DNA from each of the samples in five replicate purifications $(n=5)$, which were eluted in $1 \times$ PCR buffer. The total amount of DNA in each eluate was calculated from fluorometric DNA assay data. c, Dipsticks were used to purify the DNA from the same samples and elute it directly into a qPCR reaction with primers designed against the $P$. syringae genome. Purifications were performed in quadruplicate $(n=4)$ and qPCR quantification values $\left(2^{-C a}\right)$ were calculated. All bar graphs represent mean $\pm \mathrm{SE}$; individual points represent raw data values.

\section{Reporting Summary}

Further information on research design is available in the Nature Research Reporting Summary linked to this article.

\section{Data availability}

Raw data for the dsDNA quantification and qPCR results shown in Fig. 5 are provided as Source Data.

\section{References}

1. Bradshaw, C. J. et al. Massive yet grossly underestimated global costs of invasive insects. Nat. Commun. 7, 12986 (2016).

2. Global Burden of Disease Health Financing Collaborator Network. Global, regional, and national disabilityadjusted life years (DALYs) for 306 diseases and injuries and healthy life expectancy (HALE) for 188 countries, 1990-2013: quantifying the epidemiological transition. Lancet 386, 2145-2191 (2015).

3. Global Burden of Disease Health Financing Collaborator Network. Past, present, and future of global health financing: a review of development assistance, government, out-of-pocket, and other private spending on health for 195 countries, 1995-2050. Lancet 393, 2233-2260 (2019).

4. Kong, W. H. et al. SARS-CoV-2 detection in patients with influenza-like illness. Nat. Microbiol. 5, 675-678 (2020).

5. Zou, Y. et al. Nucleic acid purification from plants, animals and microbes in under 30 seconds. PLoS Biol. 15, e2003916 (2017).

6. Mason, M. G. \& Botella, J. R. A simple, robust and equipment-free DNA amplification readout in less than 30 seconds. RSC Adv. 9, 24440-24450 (2019).

7. Boom, R. et al. Rapid and simple method for purification of nucleic acids. J. Clin. Microbiol. 28, 495-503 (1990).

8. Moeller, J. R., Moehn, N. R., Waller, D. M. \& Givnish, T. J. Paramagnetic cellulose DNA isolation improves DNA yield and quality among diverse plant taxa. Appl. Plant Sci. 2, 1400048 (2014).

9. Koo, K., Foegeding, P. M. \& Swaisgood, H. E. Isolation of RNA and DNA fragments using diatomaceous earth. Biotechnol. Tech. 12, 549-552 (1998).

10. Kim, J. et al. A PCR reactor with an integrated alumina membrane for nucleic acid isolation. Analyst 135, 2408-2414 (2010).

11. Mason, M. G., Blackall, P. J., Botella, J. R. \& Templeton, J. M. An easy-to-perform, culture-free Campylobacter point-of-management assay for processing plant applications. J. Appl. Microbiol. 128, 620-629 (2020).

12. Hammouda, O. T., Bottger, F., Wittbrodt, J. \& Thumberger, T. Swift large-scale examination of directed genome editing. PLoS ONE 14, e0213317 (2019).

13. Martello, A., Lambert, B., Johnston, C., Cutler, J. \& Stumpf, C. F. Comparison of the novel dipstick DNA extraction technique with two established techniques for use in biological barcoding. Mol. Biol. Rep. 46, 6625-6628 (2019).

14. Sullivan, T. J., Dhar, A. K., Cruz-Flores, R. \& Bodnar, A. G. Rapid, CRISPR-based, field-deployable detection of white spot syndrome virus in shrimp. Sci. Rep. 9, 19702 (2019).

15. $\mathrm{Yu}, \mathrm{J}$. et al. Rapid and equipment-free detection of Phytophthora capsici using lateral flow strip-based recombinase polymerase amplification assay. Lett. Appl. Microbiol. 69, 64-70 (2019).

16. Zhang, Y. M., Zhang, Y. \& Xie, K. B. Evaluation of CRISPR/Cas12a-based DNA detection for fast pathogen diagnosis and GMO test in rice. Mol. Breed. 40, 11 (2020). 
17. Park, G. S. et al. Development of reverse transcription loop-mediated isothermal amplification assays targeting severe acute respiratory syndrome coronavirus 2 (SARS-CoV-2). J. Mol. Diagn. 22, 729-735 (2020).

18. Yu, L. et al. Rapid detection of COVID-19 coronavirus using a reverse transcriptional loop-mediated isothermal amplification (RT-LAMP) diagnostic platform. Clin. Chem. 66, 975-977(2020).

19. Gan, W. et al. A filter paper-based microdevice for low-cost, rapid, and automated DNA extraction and amplification from diverse sample types. Lab Chip 14, 3719-3728 (2014).

20. Qiu, X. B. \& Mauk, M. G. An integrated, cellulose membrane-based PCR chamber. Microsyst. Technol. 21, 841-850 (2015).

21. Choi, J. R. et al. An integrated paper-based sample-to-answer biosensor for nucleic acid testing at the point of care. Lab Chip 16, 611-621 (2016).

22. Choi, J. R. et al. Lateral flow assay based on paper-hydrogel hybrid material for sensitive point-of-care detection of dengue virus. Adv. Healthc. Mater. 6, 1600920 (2017).

23. Tang, R. H. et al. A fully disposable and integrated paper-based device for nucleic acid extraction, amplification and detection. Lab Chip 17, 1270-1279 (2017).

24. Liu, S. et al. Lab in a Pasteur pipette: low-cost, rapid and visual detection of Bacillus cereu using denaturation bubble-mediated strand exchange amplification. Anal. Chim. Acta 1080, 162-169 (2019).

25. Shi, R., Lewis, R. S. \& Panthee, D. R. Filter paper-based spin column method for cost-efficient DNA or RNA purification. PLoS ONE 13, e0203011 (2018).

26. Ihira, M. et al. Direct detection of human herpesvirus 6 DNA in serum by variant specific loop-mediated isothermal amplification in hematopoietic stem cell transplant recipients. J. Virol. Methods 167, 103-106 (2010).

27. Mercier, B., Gaucher, C., Feugeas, O. \& Mazurier, C. Direct PCR from whole-blood, without DNA extraction. Nucleic Acids Res. 18, 5908-5908 (1990).

28. Sidstedt, M., Radstrom, P. \& Hedman, J. PCR inhibition in $\mathrm{qPCR}$, dPCR and MPS-mechanisms and solutions. Anal. Bioanal. Chem. 412, 2009-2023 (2020).

29. Bickley, J., Short, J. K., McDowell, D. G. \& Parkes, H. C. Polymerase chain reaction (PCR) detection of Listeria monocytogenes in diluted milk and reversal of PCR inhibition caused by calcium ions. Lett. Appl. Microbiol. 22, 153-158 (1996).

30. Klatser, P. R., Kuijper, S., van Ingen, C. W. \& Kolk, A. H. J. Stabilized, freeze-dried PCR mix for detection of mycobacteria. J. Clin. Microbiol. 36, 1798-1800 (1998).

\section{Acknowledgements}

The authors thank Y. Trusov (University of Queensland) for providing the P. syringae culture used in this research.

\section{Author contributions}

M.G.M. designed and performed experiments, analyzed and interpreted the data, developed the methodology and wrote the manuscript. J.R.B. performed data interpretation, method development and editing of the manuscript. M.G.M. and J.R.B. recorded and edited the supplementary videos.

\section{Competing interests}

The authors declare no competing financial interests. The original Patent Cooperation Treaty (PCT) held by the University of Queensland, which protected the intellectual property in regard to the nucleic acid-purifying dipsticks, has now lapsed.

\section{Additional information}

Supplementary information is available for this paper at https://doi.org/10.1038/s41596-020-0392-7.

Correspondence and requests for materials should be addressed to M.G.M. or J.R.B.

Reprints and permissions information is available at www.nature.com/reprints.

Publisher's note Springer Nature remains neutral with regard to jurisdictional claims in published maps and institutional affiliations.

Received: 30 April 2020; Accepted: 31 July 2020;

Published online: 1 October 2020

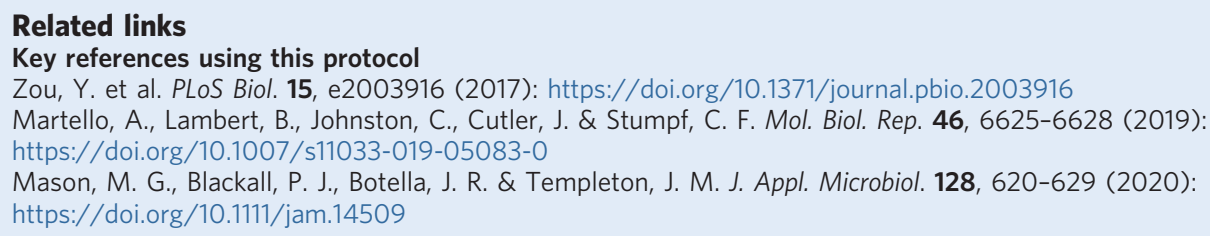




\section{Reporting Summary}

Nature Research wishes to improve the reproducibility of the work that we publish. This form provides structure for consistency and transparency in reporting. For further information on Nature Research policies, see Authors \& Referees and the Editorial Policy Checklist.

\section{Statistics}

For all statistical analyses, confirm that the following items are present in the figure legend, table legend, main text, or Methods section.

$\mathrm{n} / \mathrm{a}$ | Confirmed

$\square$ \. $\square$ The exact sample size $(n)$ for each experimental group/condition, given as a discrete number and unit of measurement

$\square$ \ A statement on whether measurements were taken from distinct samples or whether the same sample was measured repeatedly

The statistical test(s) used AND whether they are one- or two-sided

$\bigotimes$ Only common tests should be described solely by name; describe more complex techniques in the Methods section.

$\square$ \ A description of all covariates tested

$\square$ \ A description of any assumptions or corrections, such as tests of normality and adjustment for multiple comparisons

$\square$ A full description of the statistical parameters including central tendency (e.g. means) or other basic estimates (e.g. regression coefficient)

$\square$ AND variation (e.g. standard deviation) or associated estimates of uncertainty (e.g. confidence intervals)

$\triangle$ For null hypothesis testing, the test statistic (e.g. $F, t, r$ ) with confidence intervals, effect sizes, degrees of freedom and $P$ value noted

$\triangle \square$ Give $P$ values as exact values whenever suitable.

Х $\square$ For Bayesian analysis, information on the choice of priors and Markov chain Monte Carlo settings

Х $\square$ For hierarchical and complex designs, identification of the appropriate level for tests and full reporting of outcomes

$\square$ ¿stimates of effect sizes (e.g. Cohen's $d$, Pearson's $r$ ), indicating how they were calculated

Our web collection on statistics for biologists contains articles on many of the points above.

\section{Software and code}

Policy information about availability of computer code

Data collection Microsoft excel 2003 was used to collect the data. No custom code was used.

Data analysis GraphPad Prism software 8 was used to statistically analyse the data. No custom code was used.

For manuscripts utilizing custom algorithms or software that are central to the research but not yet described in published literature, software must be made available to editors/reviewers. We strongly encourage code deposition in a community repository (e.g. GitHub). See the Nature Research guidelines for submitting code \& software for further information.

\section{Data}

Policy information about availability of data

All manuscripts must include a data availability statement. This statement should provide the following information, where applicable:

- Accession codes, unique identifiers, or web links for publicly available datasets

- A list of figures that have associated raw data

- A description of any restrictions on data availability

Provide your data availability statement here.

\section{Field-specific reporting}

Please select the one below that is the best fit for your research. If you are not sure, read the appropriate sections before making your selection. $\bigotimes$ Life sciences $\quad \square$ Behavioural \& social sciences $\square$ Ecological, evolutionary \& environmental sciences 


\section{Life sciences study design}

All studies must disclose on these points even when the disclosure is negative.

Sample size

$\mathrm{n}=1$. Only 1 sample of each $\mathrm{P}$. Syringae dilution was assayed in this publication

Data exclusions

no data was excluded

Replication I have personally been using the dipstick nucleic acid purification method detailed in this manuscript for 3 years on numerous sample types. Some of this work has been published.

Randomization Randomisation of samples is not relevant to this study. The DNA purifications made from a single set of samples in this manuscript were used only to demonstrate a trend that might be expected when using the dipsticks in samples with different concentrations of nucleic acids.

Blinding Blinding is not relevant to this study as the subject of the experiment could not be influenced by unconscious experimental bias and experimental outcomes are not subjective and also not influenced by unconscious experimental bias.

\section{Reporting for specific materials, systems and methods}

We require information from authors about some types of materials, experimental systems and methods used in many studies. Here, indicate whether each material, system or method listed is relevant to your study. If you are not sure if a list item applies to your research, read the appropriate section before selecting a response.

Materials \& experimental systems Methods

\begin{tabular}{l|l}
\hline n/a & Involved in the study \\
\hline & $\square$ Antibodies \\
$\square$ & $\square$ Eukaryotic cell lines \\
$\square$ & $\square$ Palaeontology \\
$\triangle$ & $\square$ Animals and other organisms \\
$\square$ & $\square$ Clinical data
\end{tabular}

$\mathrm{n} / \mathrm{a}$ Involved in the study

$\bigotimes \square$ ChIP-seq

Х $\square$ Flow cytometry

$\bigotimes \square$ MRI-based neuroimaging 